\title{
ADOPTION OF LEAN SIX SIGMA AND THEIR TOOLS IN CONSTRUCTION ASPECT
}

\author{
DAMANELLORE KARTHIK, UMASHANKAR \\ Student,Dept.of Civil Engineering ,N.B.K.R Institute of Science And Technology, Vidyanagar \\ (Autonomous), Affiliated By Jntua Ananthapuramu, Andhrapradesh, India, Pin Code-524413 \\ *Corresponding authors: damanellorekarthik@gmail.com, umashankar19993067@gmail.com
}

\begin{abstract}
Lean six sigma is one of the systematic and chronological order approach to be focused for the greater the performance of the work, removal of unusual wastages and eliminating the defected work. The lean six sigma concept involves the ' 5 ' principles. The primary and preliminary objective of these principles is to obtain the maximum benefits with optimized economy. It consists of processes such as identification of problem, elimination of the variations or defected work and then adopt a clear communication plan within the workers for the free flow of the creative ideas. Then initiate the entire frame work into a flexible and controlled process. By use of lean six sigma any kind of problems can be analysed in an to produce a good output. They can derive maximum benefits such as adequate satisfaction of work execution with neglected defects and complete work with minimum cost. . So that we can increase the profits and productivity and performance of the work. The tools involved in the lean six sigma are 5s system, value stream mapping, kai-zen and voice of the customer. So each and every tool has their own advantages to approach the problem and provide a solution. The term lean is adequately adopted in bushiness but as in case of construction lean can be adopted as productivity tool, so that they can improve the work performance and improve the efficiency. The lean can be adopted small sized projects with little amount of time frame.
\end{abstract}

Key words: IDOV, kai zen, Lean six sigma, lean six sigma tools, '5s'system,

\section{INTRODUCTION}

Unlike traditional Six Sigma, Lean Six Sigma uses six sigma approach along with some of the methodologies from lean manufacturing. Lean Six Sigma is the evolution of the Six Sigma methodology and not the modification of Six sigma.

It is a process improvement methodology made to eliminate problems, remove waste and inefficiency, and improve working conditions for to providing a better response to needs of customers.

Six Sigma is the main agenda for many companies which try to reduce cost and improve productivity. $t$ thousands of Six Sigma projects are implemented world wide by top companies every year by investing significant capital.

\section{METHODOLOGY IDOV[Indentify-Design-Optimize-Verify]}

IDOV is a commonly used Six Sigma methodology and stands for Identify, Design, Optimize and Verify. It is a variant of DFSS or Design For Six Sigma, which is used for designing a completely new product or business process to meet customer needs and specifications or to achieve Six Sigma quality levels.

The IDOV methodology (identify, design, optimize, verify) is similar to DMAIC and is a component of the Six Sigma management system intended to guide processes involved in creating a new product, service or business process and ensure quality control.

IDOV consists of four different phases as described below. 


\section{Identify}

This phase deals with identifying the specific customer needs and product/process will designed based on the customer needs. For this customer's main communication point and desire is identified. In this phase, management professionals are required to define VOC (voice of the customer), develop a team and team charter, perform competitive analysis and identify CTQ( critical-to-quality factors)

Main Six Sigma tools used in this phase include QFD or quality function deployment, FMEA or failure means and effects analysis, SIPOC or supplier, input, product, output, customer product map, IPDS or integrated product delivery system, target costing and benchmarking.

\section{Design}

The design phase defines functional requirements, development of alternate business processes/ new products, evaluation of available options, and selection of the most appropriate business process, based on the data from first phaseThe design phase involves the concept design formulation,, risk elements and design parameters identification, and formulation of procurement plans and manufacturing plans.

\section{Optimize}

In this phase, tolerances are assessed utilizing CTQs and advanced simulation tools. This phase is also used for performance prediction and alternate designs and design elements are tested.

\section{Verify or validation}

The last phase of IDOV methodology deals with testing and validating the selected design. Changes to a business process design can be made in this phase.

Two other Six Sigma systems used for new processes are DMADV (define, measure, analyze, design, verify) and DMAIC (define, measure, analyze, improve, control).

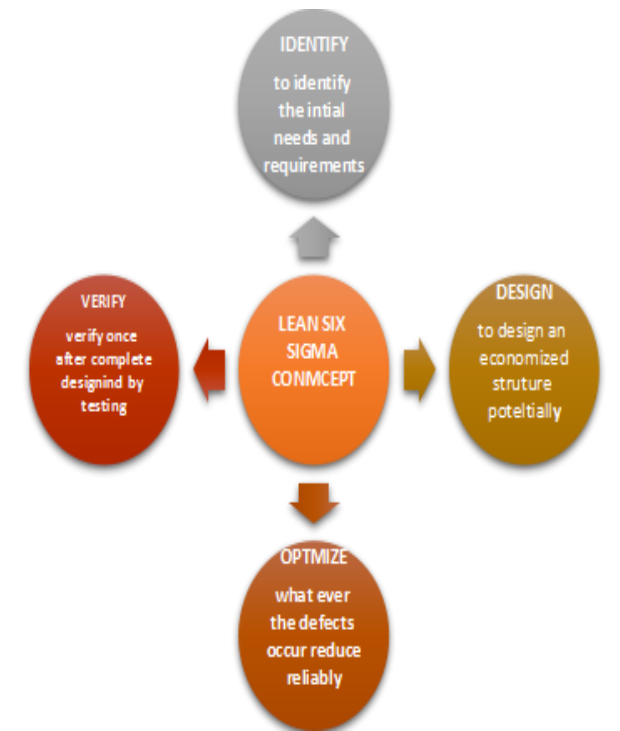

Fig 1: Methodology Of IDOV

\section{LEAN SIX SIGMA TOOLS IN CONSTRUCTION}

\section{A. '5S' SYSTEM}

The acronym of' $5 s^{\prime}$ is to sort, set in order, shine, standardize, sustain. So it is an work place defined methodology to lower defected work and greater the productivity of the work in an compatible manner.

\section{How To Adopt In Construction}

\section{Sort}

Workers sort everything in a workspace into what is and what is not needed. The Sort phase is the first step to making more effective use of space by clearing out hazardous items and unwanted that distracts from doing the job.

\section{Set}

The term refers to "Set in Order". Work place should be "A place for everything and everything in its place." Workers should position items based on use, with frequently needed items kept closer at hand. Every item that made it through the Sort stage is given storage space. 


\section{International Journal of Trendy Research in Engineering and Technology \\ Volume 5 Issue 1 February 2021 \\ ISSN NO 2582-0958}

\section{Shine}

Shine refers to cleaning. After making the cluttered storage space organized, it is the duty of workers to keep it clean. After a thorough initial cleaning, workers clean the station periodically - daily or every day twice a day depending upon the requirements. Cleaning includes storage areas, machines, equipment, tools and work surfaces.

\section{Standardize}

It refers to standardization of the processes Sort, set in order and Shine. All the employees from executive level to worker participate in the creation of set of standards which will govern the maintenance of the work place.

\section{Sustain}

Sustain refers to adopting to new rules of $5 \mathrm{~s}$ system. Workers keep the new standards in place and practice the new standards of the first three steps have to be practiced every day by the workers until they become automatic and become accepted way of doing things. The final step Sustain is the most challenging one. Proper training through good communication will eventually will lead to employees becoming comfortable with $5 \mathrm{~S}$ procedures.

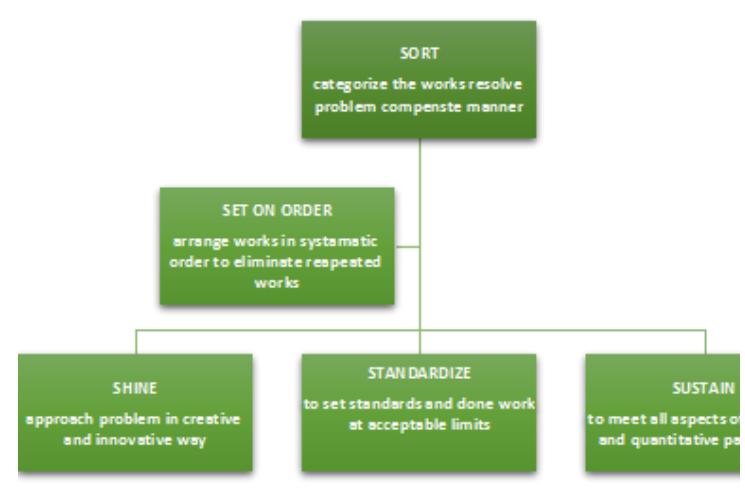

Fig2 : '5s' System

\section{B. VALUE STREAM MAPPING}

The Value stream mapping process allows you to create a detailed visualization of all steps in your work process.
A value stream map displays all the important steps of your work process necessary to deliver value from start to finish. It allows you to visualize every task that your team works on and provides single glance status reports about each assignment's progress

\section{How to adopt in construction}

In construction industry many workers are involved along with authorities,managers and project supervisors. So we can establish a systematic flow processing chart to recognize their roles based on their skills.

Then we divide the whole work into manageable departments and allocate workmen, and supervisors based on their specialized skills and also based on their efficiency and skills.

So that we monitor where defects occur and rectify defects by means to allocating superiors or supervisor for the particular work. Thus by regular monitoring we can eliminate the repeated cycling defected works and thereby improve the process by this high level process mapping.

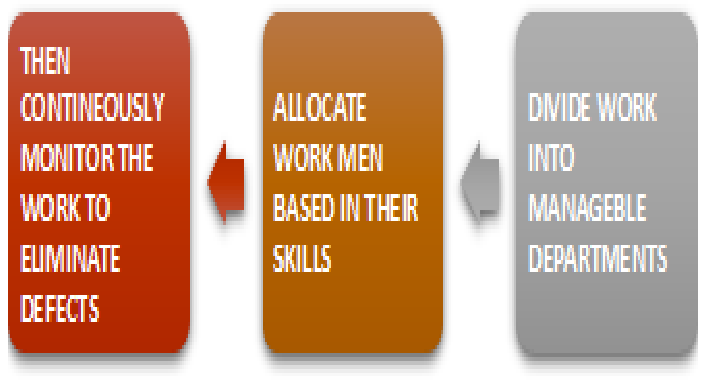

Fig 3. : Procedure For Value Stream Mapping

\section{KAIZEN}

The term or word of kai zen is derived from the japaneese terminology it means the "change for the better" or "continues improvement". so kai means(change) and zen means (good).

While kai zen is an tool evolved for the purpose of how to improve the performance of the work by assessing in a logical methodological process. 


\section{International Journal of Trendy Research in Engineering and Technology \\ Volume 5 Issue 1 February 2021 \\ ISSN NO 2582-0958}

\section{How to adopt in construction}

The kai zen consists of the following ' 5 ' important elements

Team work, personnel discipline, improve morale, quality circle, suggestion for improvement.

\section{1) Team work}

With the good amount of team work we can successfully complete the work in an efficient manner. In a team work we can get flow of information from bottom line of worker to the top line supervisor. By this concept we get to know various innovative ideas from concerned lateral thinking of workers.

\section{2) Personnel discipline}

The behavior of the workmen can vary from person to person. We can create an environment by providing certain rules and regulations to complete the work effectively, and efficiently.

\section{3) Improve morale}

This consists of following process.: initially encourage the workers based on their charcters and ability to work, conducting regular meetings and audits, giving feedback from all other workers excluding the managerial level staff, giving an adequate training to their workers and managers for their further improvement in working performance, and creating a working environment in an motivational way which may leads to gain a good output. Finally create a congenital atmosphere for the workers to share logical and creative ideas.

\section{4) Quality circle}

It is also known as control circle. In this element of work can be primarily identified based on the prominence and important objectives. Thereafter repeated defected works can be identified and resolved within the acceptable limits.

\section{5) suggestions for improvement}

The name it self indicates us that one should gave suggestion for the improvement of particular work. It involves the following processes: adoption of proper time management schedule, creating an efficient interplanetary communication between workers and managers, giving opportunity to specialized services, creating proper coordination with respect to the progress of the work, adoption of good managerial skills through continuous technical education.

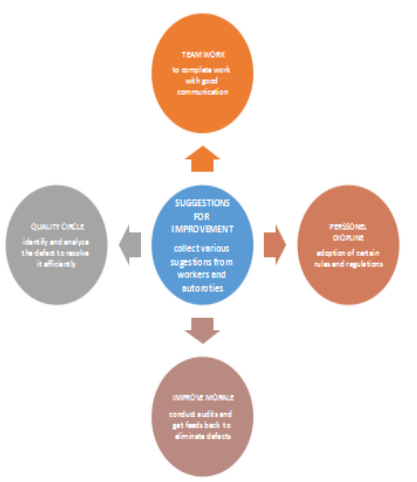

Fig 4.0 : Kai Zen System

\section{VOICE OF THE CUSTOMER}

Voice of the customer is the process of collection of all details from the client or customer with respect to their needs and requirements. The voice of the customer can give and identify the needs of customers .

\section{How to adopt in construction}

Initially we can get information from the client in a preferred $f$ structure of what we need, then what type of quality parameters we known properly, after that based on these needs and requirements we can plan the work efficiently, with an efficient and archived economy preferably.

\begin{tabular}{l}
\hline collect all details from customera \\
• such as what type of structure need, \\
•then access budjet of the project \\
\hline access the quality parametres \\
•such as materials used \\
•need of workmanship can bea known \\
\hline finally design an sustainable structure as per needs \\
and econimicamal aspects \\
•provide an economized and comfortable sturcture as per requirement \\
\hline
\end{tabular}

Fig 5 : Procedure For Voice Of Customer 


\section{ADVANTAGES OF LEAN SIX SIGMA AND THEIR TOOLS}

1. To efficiently meet the customer needs and requirements

2. To optimize the cost of construction by introducing waste eliminating principles

3. Greater the revenue and productivity of the work that we execute

4. Provision of lateral logical thinking so as to complete work effectively

5. Eliminate repeated and recyclable defected works

6. Improve the performance of the work.

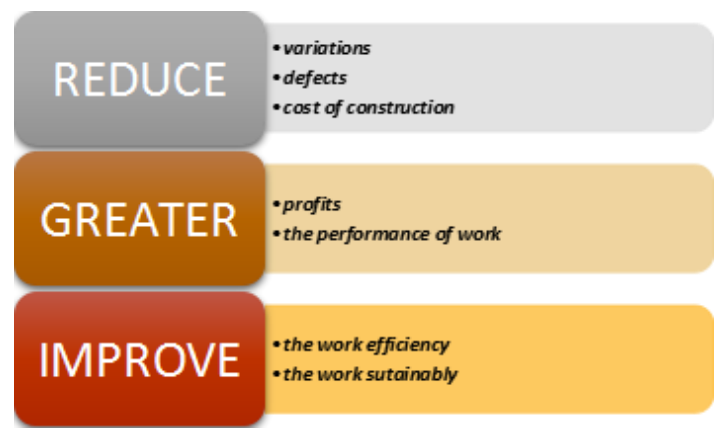

Fig 6 : Advantages Of Lean Six Sigma And Their Tools

\section{DIS ADVANTAGES OF LEAN SIX SIGMA AND THEIR TOOLS}

1. The major dis advantage of lean six sigma concept we can access the work only in a specific period. so that it requires lot of time to analyze the results form the whole process.

2. Requires an efficient analyzers for the analyzing the data

3. We have to establish an extraordinary control measure which requires very care full supervision.

4. For analyzing a lot of data, data retrieving is necessary. It requires a huge investment of time and resources for smooth complete work with optimized economy.
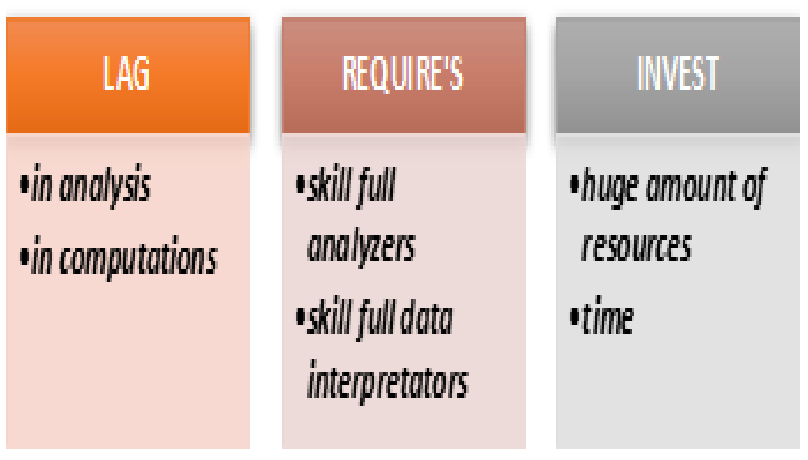

Fig 7 : Dis Advantages Of Lean Six Sigma And Their Tools

\section{CONCLUSTION}

The lean six sigma model, their tools and elements can be clearly depict how the work can meet the qualitative standards and specific quantitative requirements. With the use of lean six sigma concept we can efficiently reduce the variations of the work and eliminate the repeated defects in work effectively, If we introduce these concept in constructional concept we can improve the efficiency of the work. The elements of the lean six sigma can helps us to understand and approach the problem and subsequently solve the issue.Thus lean six sigma is an innovative and creative tool to implement then improve the performance of the work

\section{ACKNOWLEDGEMENT}

At the outset authors would like to express their profound sense of gratitude to their project guide Sri V. Venkata Rambabu, Assistant Professor, Department of Civil Engineering, N.B.K.R. Institute of Science and Technology (Affiliated to J.N.T.U.A, Ananthapuramu), Vidyanagar, for his guidance and the constant encouragement throughout the project.

Authors sincerely convey their special thanks to Sri N. RAMKUMAR, Correspondent N.B.K.R. Institute of Science and Technology, for providing excellent infrastructure in our campus for the completion of the project.

Authors are grateful to Dr. V. VIJAYA KUMAR REDDY, Director N.B.K.R Institute of 
Science and Technology for allowing us to avail all the facilities in the college.

Authors express their sincere gratitude to Dr. D. SRINIVAS, Head of Civil Engineering, for providing hardware and software facilities for successful completion of the project work.

Authors would like to convey their thanks to all Teaching faculty, Department of civil engineering who extended their cooperation in making this work a successful one.

Authors wish to convey their heartfelt thanks to Lab technicians, friends, who extended their cooperation in making this, project a successful one.

One of the authors Karthik wishs to express his thanks to his father Sri. DAMANELLORE SUBRAMANYAM, his mother SMT. DAMANELLORE DEVAYANI , and his brother DAMANELLORE AADHARSH who encouraged me to carryout this work successfully.

This work could not have been completed without the support of my classmates K. SAI KUMAR, DILEEP KUMAR, and my closest friend M. RAVI.

\section{REFERENCES}

[1] Hand Field , r. Ghosh, s.o Faweet, s., Quality Driven Change And Its Effects On Financial Performance, Quality Management Journal, 5(3), Pp: 13-30, 1998

[2] Dasgupta, t. Using Six Sigma Metric To Measure And Improve Of a Supply Chain , Total Quality Management 14(3), Pp: 355-367, 2003

[3] Coronodo, r.b., Antony, j., Critical Success Factors For The Success Full Implementation Of Six Sigma Projects In Organization, The TQM Magazine, 14(2), Pp: 92-99, 2002
[4] V. Rajasreedharan, r. Raju, a Systamatic Literature Review Of Lean Six Sigma In Different Industries, International Journal Of Lean Six Sigma, 10(4), 2010

[5] Sura j Salah, Abdul Rahim, Jaun a. Carretero.The Integration Of Six Sigma And Lean Management, International Journal Of Lean Six Sigma, 1(3), Pp: 249-254. 2010

[6] Ronald d. Snee, Lean Six Sigma Getting Better All The Time, International Journal Of Lean Six Sigma , 1(1), Pp: $9-29,2010$

[7] George m.1 , Lean Six Sigma For Service How To Use Lean Speed And Six Sigma Quality To Improve Services And Transcription, Mc Grwal Hill New York, 1993

[8] Snee r.d , Focus Improvement In Training Quality Management Forum, Spring, 8(16), Pp: 7-8

[9] Nurul Fa Day Habidin, Shari Mohd Yusuf, Critical Success Factor Of Lean Six Sigma For Malaysian a Automotive Industry, 4(1), Pp: 60-82, 2013

[10] Basu r. , Implementing Six Sigma And Lean a Practical Guide To Tools And Techniques For Better Work Heinlein Oxford 


\section{Biographies and Photographs}

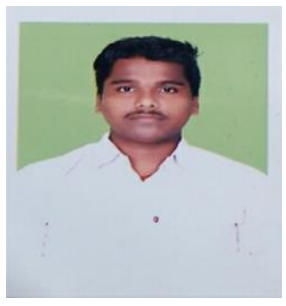

DAMANELLORE KARTHIK obtained his diploma in civil engineering from govt. Polytechnic college nellore SBTET board. Presently studying bachelor of technology in civil engineering final year in N.B.K.R institute of science and technology vidyanagar. He has published 03 research papers in international journals and he is student member of IFERP and he is interested in the research areas of civil engineering domain's and has special interest on construction planning management. With his interest he has done researches on Innovative concepts like six sigma and their methodologies in terms of construction aspect

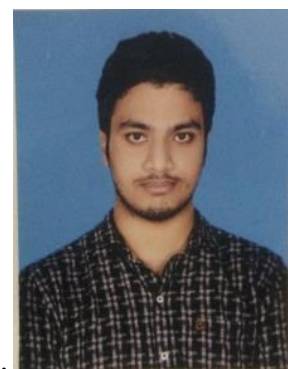

UMASHANKAR is presently studying bachelor of technology in civil engineering final year in N.B.K.R institute of science and technology vidyanagar. He is most interested in researches regarding in civil engineering perspective. His goal is to make construction field in productive way with negligible defects and it is the first paper published in journal by him. 